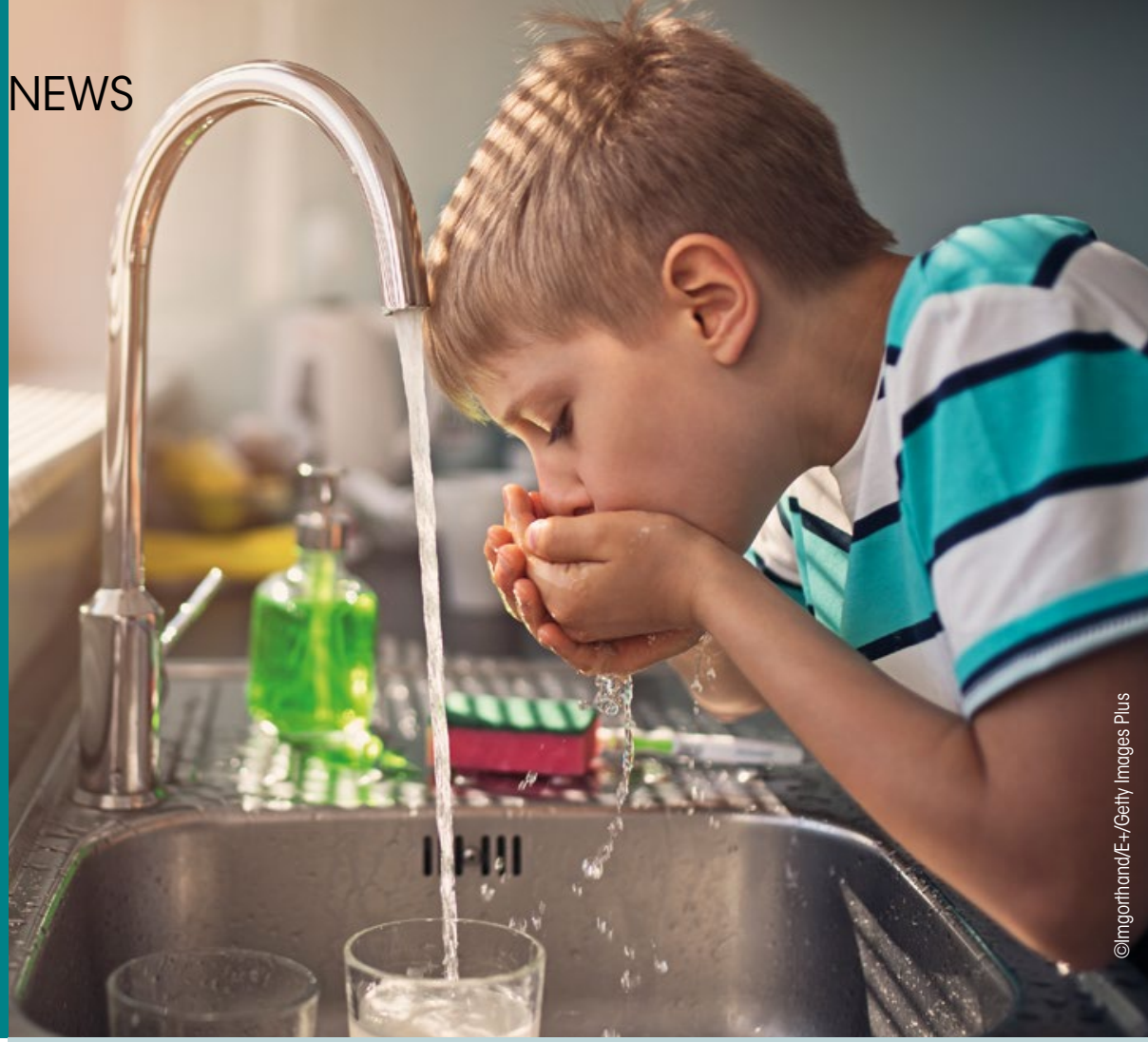

\title{
WATER FLUORIDATION GATHERS SUPPORT
}

Local Authorities and policy makers are starting to look more seriously at Community Water Fluoridation (CWF), with several making enquiries and undertaking feasibility studies.

The National CWF Network has been set up to update stakeholders and to highlight the significant benefits that Community Water Fluoridation delivers. This follows the recent lobbying led by the Royal College of Paediatrics and Child Health (RCPCH), the British Society of Paediatric Dentistry (BSPD) and the BDA to reallocate the recurrent costs of fluoridation schemes away from cash strapped councils.

Dental Teams in fluoridated areas where the benefits are clear as well as in non-fluoridated areas where disease rates are high are being encouraged to engage more actively and support local authorities taking these steps in the interests of improving oral health and reducing inequalities.

Several organisations have written to Matt Hancock, Secretary of State for Health and Social Care, as part of the consultation around the Green Paper on prevention, highlighting the role that targeted fluoridation could play as part of a comprehensive oral health strategy.

Water fluoridation in Hull has not yet become a reality but much can be learnt from their highly effective campaign.
Lobbyists created the impactful One Part per Million website: https:// onepartpermillionhull.co.uk which might well be reformulated for other areas, including Durham and South Yorkshire.

The RCPCH has published a blog which highlights ways that professionals can communicate the benefits of CWF: https://www.rcpch.ac.uk/newsevents/news/case-fluoridation-protectchildrens-oral-health.

The West Midlands CWF Scheme, introduced in 1964, is a perfect example of the benefits of fluoridation, according to the Network. Collaboration of this kind between public health, the NHS, local authorities and water companies is rarely seen.

Public Health England has provided convincing evidence of the benefits of these schemes. Their fluoridation health monitoring report (PHE, 2018) shows a $45 \%$ reduction in the numbers of children admitted to hospital for dental extractions reaching as high as $68 \%$ in the most deprived fluoridated areas.

Their most recent data (PHE, 2019) show that 2,847 0-5 year-olds were admitted to hospital for dental extractions in Yorkshire and the Humber compared with just 663 admissions in the mainly fluoridated West Midlands. With the backing of the dental profession there may be an opportunity for more communities to benefit in the near future.

\section{TINY TEETH BELONG} TO MINIATURE ANCIENT

\section{HUMAN}

A new species of ancient human, thought to have been under $4 \mathrm{ft}$ tall and adapted to climbing trees, has been discovered in the Philippines. The tiny teeth suggest the human would have been shorter than $4 \mathrm{ft}$ tall - possibly even shorter than another ancient species, such as Homo Floresiensis, sometimes called the 'hobbit', also found in south-east Asia and dating to about the same period.

\section{Toothfairy at the palace:}

Claire Stevens, spokesperson for the British Society of Paediatric Dentistry and author of the toothfairyblog.org, with the CBE she was awarded in the New Year's Honours List for services to children's oral health. She was presented with the award by His Royal Highness the Prince of Wales. Afterwards she commented: "I am inspired by countless colleagues from the field of paediatric dentistry, past and present who have brought recognition to our specialty. I speak for them and for the millions of children in the UK who have a right to the best possible start to their oral health. I believe our Dental Check by One campaign is axiomatic to delivering on our aim and to reducing inequalities and I am truly grateful to all those who have supported the campaign:

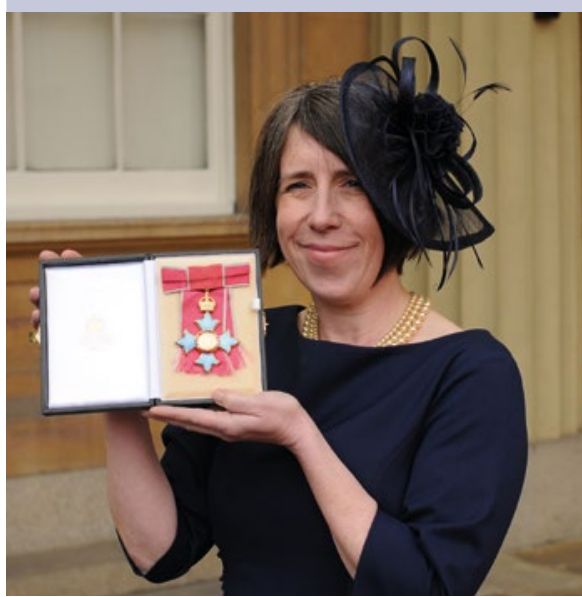

